\title{
Dilemas do UASB
}

\begin{abstract}
Marcelo Kenji Miki
Engenheiro civil (1991) MSC em engenharia civil pela USP (1998) atualmente é coodernador de projetos de pesquisa na Companhia de Saneamento Básico do Estado de São Paulo. (*)Endereço:Laboratório

\author{
Endereço: Av. do Estado, 561 / CEP 01107-900 / Bom Retiro / SP \\ E-mail:mmiki@sabesp.com.br \\ Recebido: 10/02/2010 - Aceito:18/03/2010
}

\section{INTRODUÇÃO}

De acordo com o filósofo Karl Popper, a evolução da tecnologia se dá através do método da tentativa e erro, sendo necessária a ocorrência de uma discussão crítica de forma a se eliminar estes erros. Este modelo pode ser divido em 4 fases: o problema, as tentativas de solução, a eliminação de soluções mal sucedidas e finalmente, novos problemas. Podemos aplicar este modelo na utilização da tecnologia UASB (Upflow Anaerobic Sludge Blanket/Reator Anaeróbio de Manto de Lodo) e afirmar que o atual estágio deste desenvolvimento se encontra na fase 4, ou seja, novos problemas.Ainda segundo Popper, toda discussão inicia-se da observação focada nos problemas e para isto deve-se, em primeiro lugar, admitir que haja problemas. Quando se admite que ocorram problemas numa determinada tecnologia, não há uma intenção inicial de que esta tecnologia seja eliminada. E admitida a existência de problemas, há a necessidade de se observá-las e se propor críticas às tentativas de resolução. Ao se fazer estas críticas, corre-se o perigo de que sejam interpretadas no âmbito pessoal e não no âmbito técnico. A tecnologia UASB no Brasil vem sofrendo desconfiança ao longo dos anos. Em suas primeiras implantações, muitas vezes foram vendidas esperanças de eficiências equivalentes a um tratamento secundário e descuidos na questão de odor. Na segunda onda de implantação, que vem ocorrendo nesta primeira década do milênio, a implantação de UASBs vem combinada com um pós-tratamento. No entanto ainda se observa que novos problemas surgem e necessita-se de uma maior discussão técnica para a resolução destes problemas. E, ainda, de uma forma um pouco mais pessimista, surgem dilemas ao se utilizar a tecnologia UASB. Conforme o Dicionário Aurélio, dilema é uma situação embaraçosa com duas saídas difíceis ou penosas.Segundo Popper, só o método crítico explica o crescimento extraordinariamente rápido da forma científica de conhecimento. Todo o conhecimento précientífico é dogmático e a ciência começa com a invenção do método crítico não dogmático.O que pretendemos neste artigo é através da observação dos problemas e dilemas constatados principalmente na área operacional, iniciar uma discussão crítica de modo melhorar as concepções dos UASBs.

\section{Fundamentos da tecnologia UASB}

De acordo com FORESTI et al (1999), um dos principais atrativos da tecnologia UASB como principal unidade de tratamento biológico de esgoto deve-se, principalmente, à constatação de que fração considerável do material orgânico (em geral próxima de $70 \%$ ) pode ser removida, nessa unidade sem o dispêndio de energia ou adição de substâncias químicas auxiliares.O emprego de um processo anaeróbio é muito favorecido na ocorrência de temperaturas acima de $20^{\circ} \mathrm{C}$ no esgoto, sendo que o parâmetro cinético afetado é a velocidade específica de utilização de substrato, o que favorece a aplicação desta tecnologia nos países tropicais. Já outra vantagem citada na literatura é a menor produção de lodo resultante de um processo anaeróbio. O tratamento de esgoto tem como objetivo principal a remoção do material orgânico do esgoto, que se dá principalmente através da ação de bactérias. Os mecanismos utilizados pelas bactérias são o anabolismo e o catabolismo.

Quando a bactéria utiliza o material orgânico como fonte de material e transforma em massa celular, denomina-se este mecanismo de anabolismo ou assimilação. Já no catabolismo, o material orgânico é usado como fonte de energia por meio de sua conversão em produtos estáveis, liberando energia, parte da qual é usada pelas bactérias no processo de anabolismo. Em processos anaeróbios, ocorre o chamado catabolismo fermentativo que tem como produtos finais o metano e o dióxido de carbono, que são produtos estáveis e não mais susceptíveis a outras fermentações. De acordo com GONÇALVES, LUDUVICE (2000) a massa de lodo digerido produzido na associação anaeróbio + aeróbio corresponde a cerca de $60 \%$ da produzida no aeróbio simples (com lodo misto digerido).Ou seja, de forma geral um tratamento biológico de esgoto transforma o material orgânico em novas células através do anabolismo e em produtos finais, como por exemplo, $\mathrm{CO}_{2}$, $\mathrm{CH}_{4}$ e $\mathrm{H}_{2} \mathrm{O}$, através do catabolismo. Para a avaliação comparativa entre a produção de lodo nos processos aeróbios e anaeróbios de tratamento é primordial saber a proporção de processamento entre os mecanismos de anabolismo e catabolismo destes tratamentos. De acordo com VAN HAANDEL; ALEM SOBRINHO (2006) no processo anaeróbio a proporção entre anabolismo e catabolismo está na faixa de $1: 13$, enquanto que num processo aeróbio é de $2: 1$. Outro parâmetro que exemplifica a menor produção de lodo é através da constatação da fração de material orgânico metabolizado convertido em massa bacteriana de $0,67 \mathrm{~kg} \mathrm{SVS} / \mathrm{kg} \mathrm{DQO}_{\text {met }}$ para tratamento aeróbio e de 0,07 $\mathrm{kg} \mathrm{SVS} / \mathrm{kg} \mathrm{DQO}{ }_{\text {met }}$ para tratamento anaeróbio.Em termos de evolução, os tratamentos anaeróbios foram diminuindo as suas dimensões, obtidas através do melhor conhecimento dos fenômenos do tratamento, que pôde ser verificada através da diminuição dos tempos de detenção hidráulica: lagoa anaeróbia, 3 a 5 dias; decanto digestor, de 12 a 24 horas; UASB, 6 a 10 horas. Para que os fundamentos do tratamento anaeróbio expostos anteriormente fossem aplicados na prática, desenvolveu-se o UASB, que consiste num único reator, onde na parte superior estão associados o decantador e o separador trifásico (gás, sólido e líquido), conforme ilustrado na figura 1.

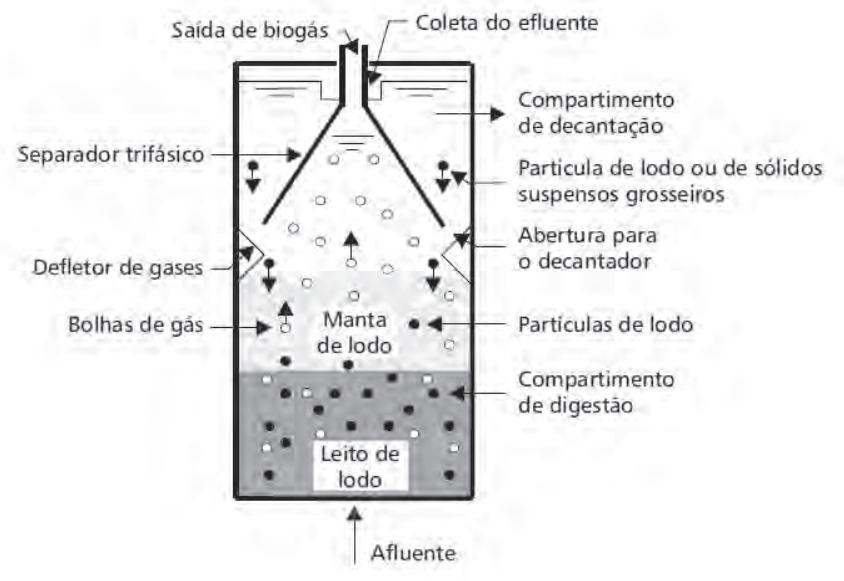

Figura 1: Desenho esquemático de um reator UASB.

Fonte: CHERNICARO et al (1999)

O esgoto a ser tratado é introduzido de forma distribuída uniformemente pelo fundo do reator e atravessa as camadas de leito, com elevada concentração de sólidos, e manto de lodo, de concentração mais dispersa que o leito. Os defletores de gás direcionam as bolhas de biogás para a campânula de coleta, enquanto que o líquido mais os sólidos em suspensão são dirigidos para o compartimento da zona de decantação, onde grande parte destes sólidos se sedimenta e retorna para o fundo 
do reator. Da descrição feita do processo, verifica-se que o separador trifásico é um elemento primordial no funcionamento do UASB. Suas principais características foram sumarizadas por LETTINGA, POL (1991) conforme tabela 1 a seguir.

1. Separar e descartar o biogás do reator

2. Prevenir de forma mais eficientemente possível a lava gem do material bacteriano viável

3. Permitir que o lodo retorne para o compartimento de digestão

4. Servir como uma barreira para expansões excessivamente rápidas do manto de lodo (que é composto principalmente de lodo floculento) para o decantador

5. Providenciar um efeito de polimento.

6. Prevenir a lavagem de lodo granular flotante

Tabela 1: Principais objetivos do separador trifásico para UASB

Aplicação prática da tecnologia UASB no Brasil

De acordo com ALEM SOBRINHO; KATO (1999), o desenvolvimento dos UASBs no Brasil foi impulsionado inicialmente por pesquisadores da CETESB, Escola de Engenharia de São Carlos (USP), do IPT - Instituto de Pesquisa Tecnológicas e SANEPAR. Estas pesquisas tiveram como fundamento as experimentações desenvolvidas pelo Professor holandês Gatze Lettinga na década de 70.A segunda onda de desenvolvimento ocorreu com o PROSAB/Programa de Pesquisas em Saneamento Básico, financiado pelo FINEP-Financiadora de Estudos e Projetos e CNPq/Conselho Nacional de Desenvolvimento Científico e Tecnológico, do Ministério da Ciência e Tecnologia/MCT. Foi formada uma rede com 15 universidades para estudar o pós-tratamento de UASB.Fruto destas intensas pesquisas é a adoção do UASB como parte do sistema de tratamento junto aos prestadores do serviço de saneamento. No Estado de São Paulo, a aplicação da tecnologia UASB nos sistemas operados pela SABESP ocorreu de forma muito restrita e como exemplos, podem ser citados os sistemas de Ribeirão Pires, Boituva e Cesário Lange implantados na década de 90. Somente nos últimos anos vêm ocorrendo na SABESP uma maior elaboração de projetos com UASBs, justamente devido aos conhecimentos adquiridos das pesquisas desenvolvidas. Entre os projetos em desenvolvimento na SABESP, encontra-se em fase de construção a ETE de Campo Limpo/ Várzea Paulista com capacidade nominal de $560 \mathrm{~L} / \mathrm{s}$ através de UASB e lodos ativados com decantação alternada. Já em Campinas, a maioria das ETEs de maior porte foram todas concebidas com UASB. As duas maiores ETEs da região de Campinas são a ETE Anhumas, inaugurada em 2007, com capacidade nominal de $1200 \mathrm{~L} / \mathrm{s}$, composto por UASB, Tratamento Físico-Químico e Flotação por Ar Dissolvido e a ETE Piçarrão, inaugurada em 2004, com capacidade nominal de $556 \mathrm{~L} / \mathrm{s}$, composto por UASB, Lodos Ativados e Flotação por ar dissolvido.

A ETE Piracicamirim/Piracicaba foi um dos primeiros UASB de grande porte com $500 \mathrm{~L} / \mathrm{s}$ de capacidade nominal e implantada em 1998. No Estado do Paraná, a aplicação da tecnologia UASB é mais antiga que em São Paulo e iniciou-se na década de 80, resultante dos estudos promovidos pela Diretoria de Pesquisa e Desenvolvimento da SANEPAR, segundo GOMES (2004). Este pioneirismo da SANEPAR foi reconhecido através da recepção do Prof ${ }^{\circ}$ Lettinga, que viu implantada em escala real a aplicação do UASB em esgoto sanitário e promoveu a ida dos técnicos brasileiros a Cali/Colômbia e Massachussets/EUA. E ainda segundo GOMES (1981), naquela época a SANEPAR decidiu adiar a implantação de novas estações de tratamento de esgoto devido às pesquisas de desenvolvimento em andamento na época e migrou das tecnologias aeróbias para anaeróbias de tratamento.

No Estado de Minas Gerais foi implantada em 2006 a ETE Ribeirão do Onça, de Belo Horizonte, que é uma das maiores unidades de UASB que se tem notícia. No caso da ETE Onça, previu-se a implantação

progressiva de UASBs em $1^{\mathrm{a}}$ etapa e o tratamento aeróbio, com Filtros Biológicos Percoladores em $2^{\mathrm{a}}$ etapa, devido a uma maior flexibilidade no licenciamento ambiental neste Estado.No Distrito Federal, dos 17 sistemas instalados (capacidade nominal de $5960 \mathrm{~L} / \mathrm{s}$ ), 12 sistemas possuem UASBs como parte do tratamento (capacidade nominal de $3303 \mathrm{~L} / \mathrm{s}$ ), sendo que a ETE Melchior implantada em 2005 é a de maior porte (capacidade nominal de $1469 \mathrm{~L} / \mathrm{s}$ ), conforme informações obtidas em CAESB (2008).Apesar das vantagens já citadas da tecnologia UASB, a qualidade do efluente final dificilmente atinge o parâmetro de remoção de carga de $\mathrm{DBO}$ de um tratamento secundário. A promessa indevida de projetistas que alegavam remoção equivalente a um tratamento secundário aeróbio e o descuido relativo aos problemas de odor levaram a um comprometimento da credibilidade desta tecnologia diante de várias companhias operadoras de saneamento e órgãos de controle ambiental.Posteriormente, com o devido reconhecimento da necessidade de um pós-tratamento após o UASB, muitos projetos de ETEs incorporaram o UASB como uma das etapas de processo e ocupando o lugar do decantador primário, adensador de lodo primário e digestor.

\section{Questão da escala de atendimento}

A questão da escala de um UASB é um importante aspecto que merece uma reflexão mais atenta desta tecnologia. De forma grosseira, um UASB de grande porte nada mais seria que a somatória de pequenos UASBs. De forma diferente que, por exemplo, um decantador secundário circular que possui uma entrada e um único vertedor de saída, num UASB teríamos múltiplas entradas e múltiplas saídas. A ocorrência de várias saídas de descarte de excesso de lodo leva a necessidade de vários acionamentos para a realização desta operação. Na ETE Matão previuse a introdução de válvulas de acionamento automático de remoção de lodo (Figura 2), o que não ocorreu na ETEs Anhumas (Figuras 3 e 4), Piçarrão e Onça, elevando assim a carga de trabalho, mas diminuindo os investimentos. Esta abordagem de não se ter ETEs de grande porte foi uma das diretrizes adotadas pela SANEPAR na década de 80 , que considerava bacias de esgotamento atendendo entre 5000 a 100.000 habitantes, conforme GOMES (1983). Já em relação à modulação de UASBs, POL, LETTINGA (1989) apud VIEIRA; GARCIA JR (1992) recomendavam um volume máximo de $400 \mathrm{~m}^{3}$, pois volumes maiores não apresentariam vantagens adicionais relativos aos aspectos de estrutura e requisitos de operação/manutenção.

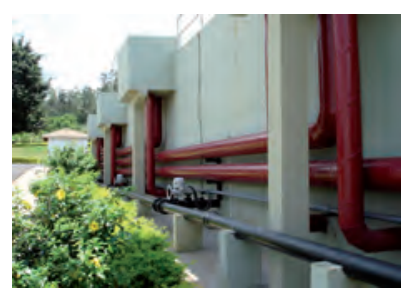

Figura 2:

Válvulas motorizadas de descarte de lodo da ETE Matão

Apesar desta recomendação de volume máximo por reator de 400 $\mathrm{m}^{3}$, em 1990 foi feito a ETE Río Frío, Bucaramanga, Colômbia, modulado com 2 unidades de $3300 \mathrm{~m}^{3}$ cada e capacidade total de projeto de $359 \mathrm{~L} / \mathrm{s}$, conforme descrito por SCHELLINKHOUT, COLLAZOS (1992). No Brasil, em 2006 foi implantada a ETE Onça/ MG com 24 reatores com volume de $2211,9 \mathrm{~m}^{3}$, e com capacidade

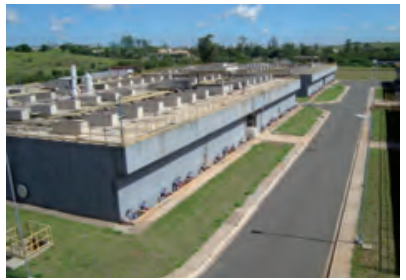

Figura 3: UASB de Anhumas Válvulas manuais de remoção de escuma e lodo

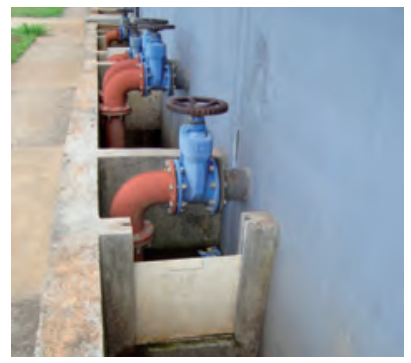

Figura 4: Válvulas manuais de remoção de escuma e de lodo da ETE Anhumas 


\section{práticas operacionais e de empreendimentos}

atual instalada de $1,8 \mathrm{~m}^{3} / \mathrm{s}$ (910.000 habitantes) e com previsão de ampliação para $3,6 \mathrm{~m}^{3} / \mathrm{s}$ (1.600.000 habitantes). A hipótese levantada para contra-argumentar um reator com volume máximo de $400 \mathrm{~m}^{3}$ é a incorporação de tecnologias que reduzissem custos, como por exemplo, sistema separador trifásico com lona, automação no acionamento de válvulas (Figuras 5 e 6), estruturas pré-moldadas, construção de UASB em taludes, etc.

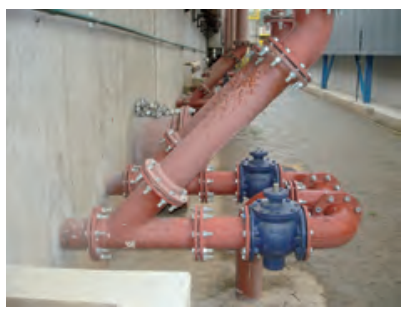

Figura 5: Válvulas do tipo esfera excêntrica da ETE Onça com acionamento manual
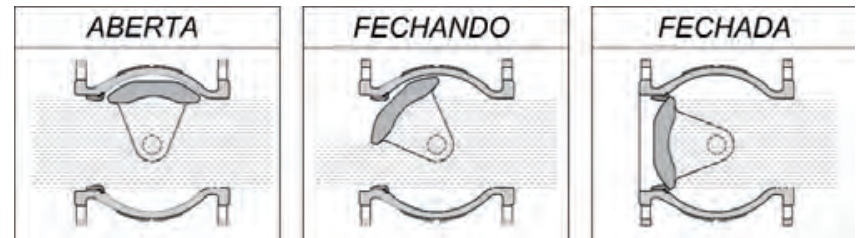

Figura 6: Princípio de funcionamento da válvula esfera excêntrica

O que merece ênfase é o aparecimento do seguinte dilema: em ETEs de grande porte: ao se optar pela tecnologia UASB, deve-se prever se a operação será feita de forma automatizada ou manual na remoção do descarte de lodo. Se for feita de forma automatizada devem ser previstas válvulas automatizadas, que podem somar recursos significativos já que não é muito evidente a economia de escala. Caso se opte pelo manual, devem ser previstos os recursos humanos necessários para a realização destas tarefas e que são muito facilmente relevadas. O cenário mais pessimista é a não adoção de sistema com válvulas automatizadas e a não previsão ou manutenção dos recursos humanos necessários, levando a uma operação problemática e conseqüentemente gerando desconfiança desta tecnologia.

\begin{tabular}{|c|c|}
\hline \multicolumn{2}{|c|}{ Dilema: Automatizar ou não peneiramento do esgoto bruto (de pelo menos $6 \mathrm{~mm}$ ) } \\
\hline Automatizar & Manual \\
\hline $\begin{array}{l}\text { Custo elevado de equipamento. } \\
\text { Opcionais de lavagem e compactação de } \\
\text { material levam a uma melhor manipulação } \\
\text { dos resíduos, mas elevam os custos de } \\
\text { investimento. }\end{array}$ & $\begin{array}{l}\text { Alta demanda de mão de obra. } \\
\text { Caso não operado adequadamente, foco de } \\
\text { atração de vetores e odores. }\end{array}$ \\
\hline
\end{tabular}

\section{Tratamento preliminar}

Atualmente há uma tendência de se restringir cada vez mais a abertura dos dispositivos de retenção de material grosseiro conforme KELLER et al (2006), através da adoção de peneiras com abertura igual ou menor a $6 \mathrm{~mm}$. Quando há membranas esta restrição aumenta entre 1 a 3 mm.Na SABESP, os projetos de ETEs da Diretoria de Sistemas Regionais (Litoral e Interior) já incorporam pelo menos uma peneira de $6 \mathrm{~mm}$, independente do tipo de tratamento posterior. Na RMSP, os problemas da falta de uma menor abertura no tratamento preliminar foram detectados na fase sólida do tratamento e solucionados através da introdução de peneiras do tipo Aqua-Guard para o lodo nas ETEs Barueri e ABC. Na ETE São Miguel a mudança de abertura foi feita no tratamento preliminar do esgoto bruto.No Brasil, alguns projetistas vêm recomendando para o UASB a utilização prévia de peneira e caixa de gordura de modo a minimizar a ocorrência de formação da escuma.
No entanto SOUZA (2006) realizou um peneiramento de $1 \mathrm{~mm}$ no esgoto e não notou diferenças na taxa de formação deste material. Já a introdução de peneira é recomendável de modo e evitar entupimentos e /ou acúmulos nos sistemas de alimentação ou saída. Esta abordagem foi feita nas ETEs com UASB mais recentes da SANASA, onde se adotou um peneiramento de $3 \mathrm{~mm}$ conforme GRANDIN (2009). Já o sistema U-Box da Dedini prevê a utilização de uma peneira de $1 \mathrm{~mm}$.

Quanto à avaliação da caixa de gordura não se encontrou relatos sobre a influência na taxa de formação de escuma. Normalmente a introdução de peneiras não elimina a necessidade de se fazer um gradeamento fino, de 10 a $20 \mathrm{~mm}$. Ou seja, o peneiramento não deve ser utilizado como substituto do gradeamento fino e sim como complemento.Do ponto de vista operacional, os problemas de deposição de material grosseiro em canais e outras unidades são solucionados, mas devem ser redobrados os cuidados relativos a odor, devido à maior retenção de material. Há equipamentos que minimizam os problemas de odor, através da adoção de dispositivos de lavagem do material retido e compactação.Uma observação a ser feita, um tanto óbvia para algumas pessoas e outras nem tanto, é a necessidade de se prever instalações para o adequado recolhimento de material percolado, tanto da caixa de areia como do gradeamento/peneiramento.

Na SABESP, algumas ETEs foram submetidas à auditoria de ISO 14.000 e uma das não conformidades mais apontada é o lançamento dos percolados em galerias de água pluviais.A título de exemplo, mostrase este problema na ETE Anhumas/SANASA, onde não foi previsto o recolhimento do percolado do gradeamento fino, conforme figura 7 .

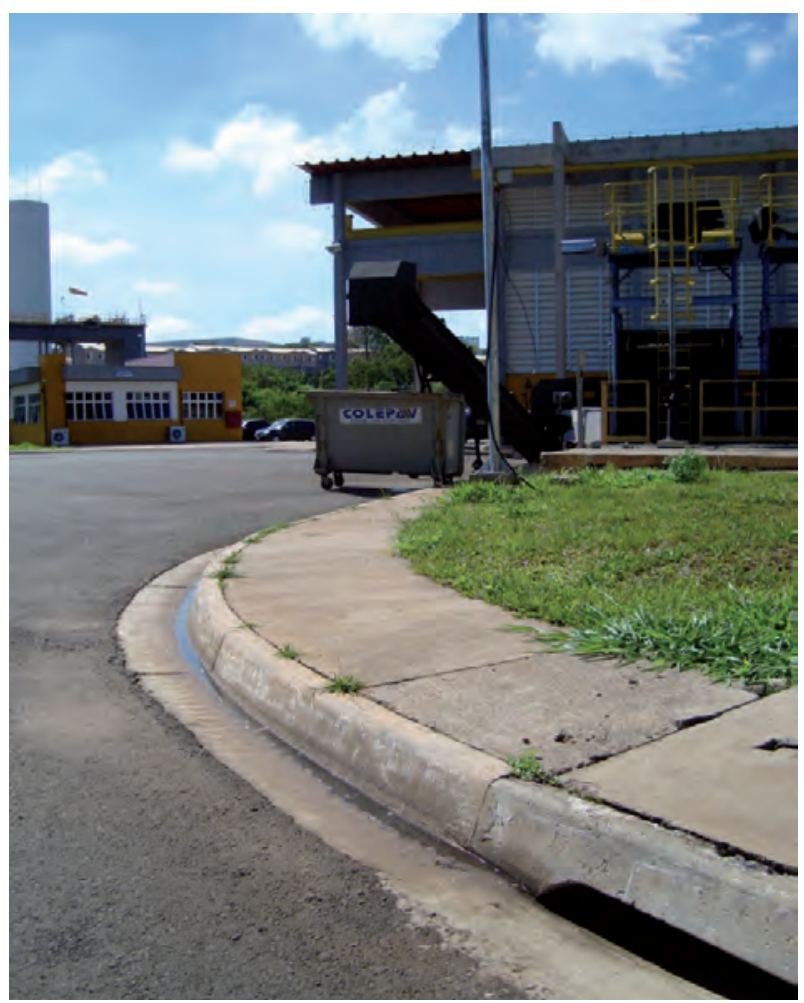

Figura 7: Percolado da caçamba do material de gradeamento fino

Devido a este problema, a área operacional está providenciando as devidas adequações como já foram feitas para o peneiramento de $3 \mathrm{~mm}$, onde se vê o recorte do chão para a introdução de tubulação de coleta de percolado. Também foram desenvolvidas caçambas com drenos para recolhimento de percolado, conforme figuras 8 e 9. 


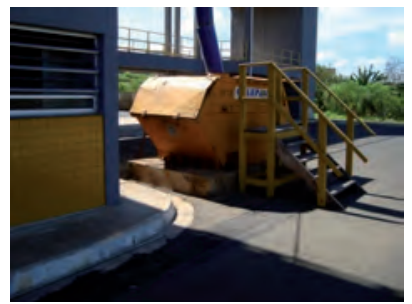

Figura 8:

Caçamba de material peneirado e detalhe de piso recortado para passagem de tubulação

Este tipo de erro não previsto na etapa de projeto, apesar de ser solucionável, acaba consumindo muito tempo e dinheiro da área operacional, recursos estes muito escassos após o recebimento da obra.

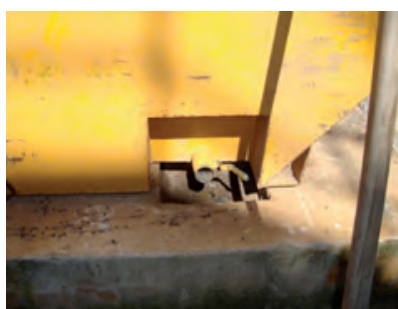

Figura 9:

Caçamba com dreno de percolado

\begin{tabular}{|l|l}
\hline Dilema: Automatizar ou não peneiramento do esgoto bruto (de pelo menos 6 mm) \\
\hline Automatizar & Manual \\
\hline Custo elevado de equipamento. & Alta demanda de mão de obra. \\
Opcionais de lavagem e compactação de & Caso não operado adequadamente, foco de \\
material levam a uma melhor manipulação & atração de vetores e odores. \\
dos resíduos, mas elevam os custos de & \\
investimento. & \\
\hline
\end{tabular}

\section{Distribuição de esgoto bruto dentro do UASB}

A tecnologia UASB se processa de modo que o fluxo de entrada de esgoto seja feito de forma mais distribuída possível em sua superfície de baixo. A remoção de excesso lodo também deve ser feita de forma uniforme.CHERNICARO et al (1999) teceram recomendações sobre os sistemas de distribuição de entrada no UASB. Mesmo assim na prática encontram-se concepções que não levaram em conta estas recomendações e que levam a problemas operacionais.Uma concepção de projeto passível de crítica é a adoção de sistemas que não permitem a identificação de pontos de entupimento, podendo ser citado, como exemplos, sistemas com ramificações no sistema de distribuição. As figuras 9 e 10 mostram um exemplo de distribuição que apresenta esta concepção. Este tipo de distribuição com divisões internas ("manifolds") já havia sido condenada por VIEIRA, GARCIA JR (1992).

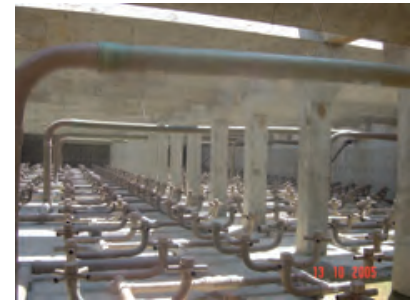

Figura 10a: Implantação de sistema de distribuição com derivação
Conforme descrição feita por RAMOS et al (2008), a ETE Gama/ DF apresenta um sistema de distribuição com tubos perfurados progressivamente. Este tipo de sistema também é passível de críticas, pela dificuldade de identificação de entupimentos, além da dificuldade de se calcular a distribuição progressiva e igualitária destas vazões.Um bom exemplo de concepção para a entrada de esgoto bruto pode ser encontrada na ETE Onça, da COPASA, Belo Horizonte/MG, com um sistema do tipo tulipa, conforme figuras 11, 12, 13 e 14. Neste tipo de alimentação há a possibilidade de identificar em cada tubulação de entrada a ocorrência de entupimento, bem como permitir o acesso para provocar um desbloqueio.

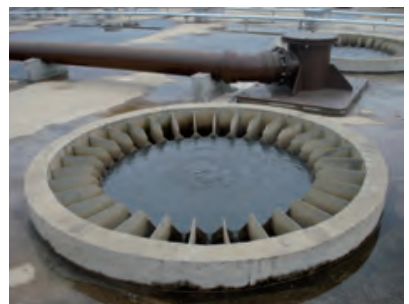

Figura 11: Visão geral do sistema de entrada de esgoto no UASB da ETE Onça

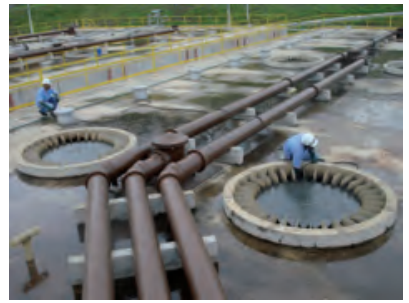

Figura 13: Detalhe da entrada

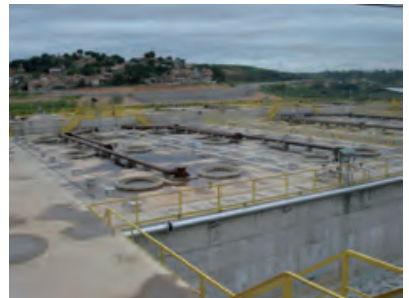

Figura 12: Detalhe da tulipa

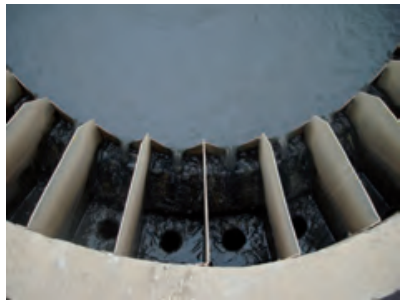

Figura 14:

Operação de desentupimento de cada bocal de entrada
A ETE Ribeirão Pires, de implantação mais antiga, também apresenta um sistema de distribuição com uma tubulação isolada por entrada (Figura 15).

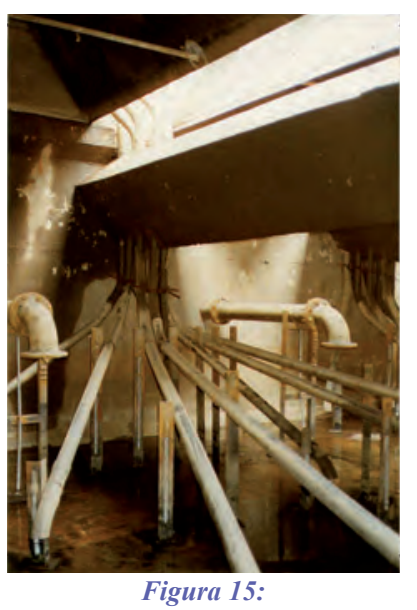

Sistema de alimentação de tubos do UASB de Ribeirão Pires

\section{O problema da escuma}

Um dos principais problemas da tecnologia UASB é a formação e acumulação de escuma tanto na área de decantação como no separador trifásico, conforme ilustrado na figura 16. A falta da previsão de dispositivos devidamente projetados e instalados para a retirada desta escuma fatalmente leva a problemas operacionais de difícil resolução posterior. 


\section{práticas operacionais e de empreendimentos}

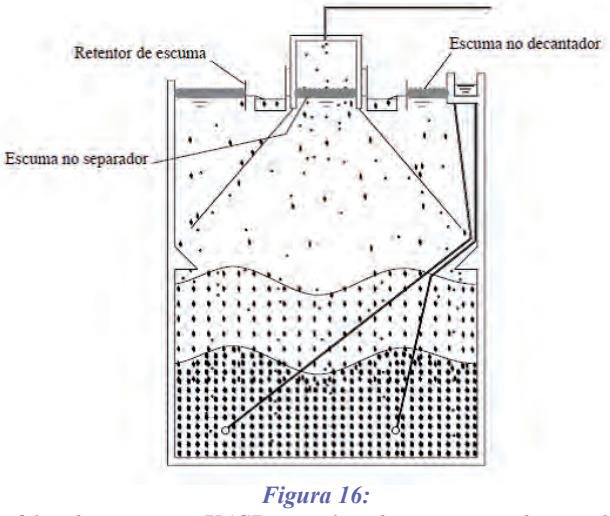

com vista da escuma no decantador e interior do separador - Fonte: SOUZA (2006)

A escuma é formada basicamente por óleos e graxas que se acumulam ao longo do tempo na superfície. O problema da escuma fica muito agravado no separador trifásico com campânulas feitas de fibra de vidro. A escuma formada no separador trifásico acaba se endurecendo e aprisiona o gás através do desenvolvimento de um selo. Esta contínua produção de gás não é detectada na linha de saída de gás da campânula.

Já a pressão debaixo da camada de escuma aumenta a tal ponto de romper abruptamente este selo e provocando uma movimentação das placas endurecidas e a torção das campânulas. Este tipo de acidente foi o que ocorreu nas ETEs Lajeado de Botucatu/SP e Piracicamirim de Piracicaba/SP.Para a escuma formada na área de decantação, recomenda-se que seja realizada a remoção contínua deste material através da saída em conjunto com o efluente. Como já é de consenso a existência de pós-tratamento após o UASB, esta unidade poderia acrescentar um tratamento adicional ou mesmo que se despreze este processo, o acréscimo de carga orgânica no efluente final ocorre de forma marginal.

Conforme VAN HAANDEL; LETTINGA (1994) apud SOUZA (2006), uma investigação feita em Kampur, Índia, entre reatores com e sem cortina escumadeira, revela pequenos incrementos na qualidade do efluente com a introdução do dispositivo. De fato, SOUZA (2006) acabou realizando medições neste incremento e encontrou valores muito baixos.A remoção contínua de escuma parte do pressuposto de que em UASBs com utilização de calhas vertedoras triangulares na área de decantação e sem cortina escumadeira não se observa a formação de escuma, ao contrário do que se constata na utilização de tubulação perfurada, conforme ilustrado nas figuras 17 e 18 .

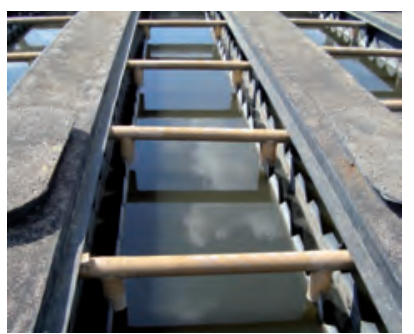

Figura 17: Saída de efluente na área do UASB de Ribeirão Pires/SP

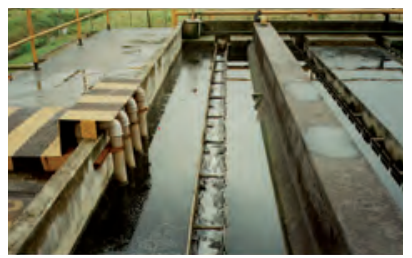

Figura 18: Saída de efluente na área do UASB de Piçarrão/SP
Com a utilização de tubulação perfurada para retirada do efluente, apesar das vantagens citadas por CHERNICARO et al (1999), há o favorecimento do acúmulo de escuma na área do decantador, conforme ilustrado nas figuras 19 e 20 do UASB da ETE Matão/SP e figura 21 da ETE Melchior/DF.
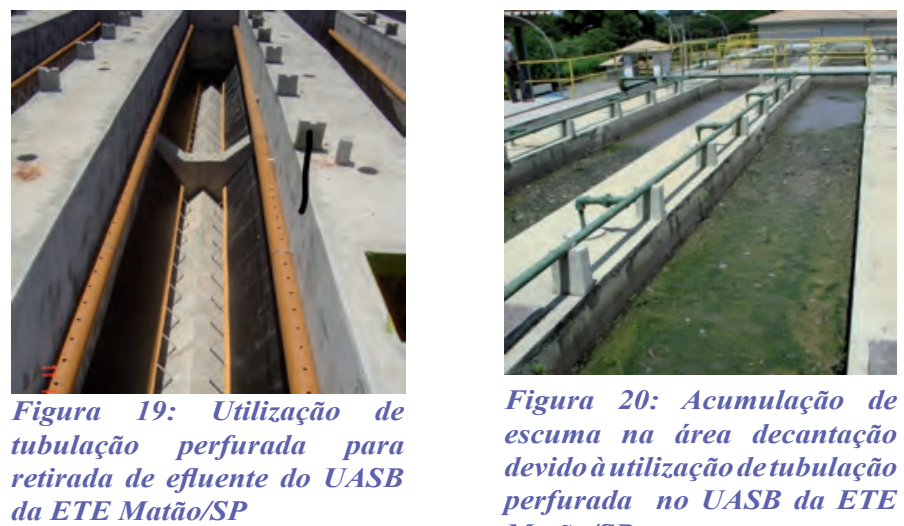

Figura 20: Acumulação de escuma na área decantação devido à utilização detubulação perfurada no UASB da ETE Matão/SP

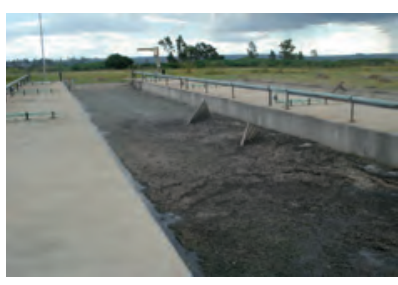

Figura 21:

Escuma na área de decantação do UASB da ETE

Este tipo de solução foi a adotada por GOMES et al (2007) no Paraná, através da remoção de cortina escumadeira que estava instalada ao lado dos vertedores triangulares. Entre outros problemas, a presença deste dispositivo leva a necessidade de outros acessórios para a retirada deste material e, consequentemente, uma maior rotina operacional. A remoção da escumadeira também foi a estratégia adotada na ETE Onça/ $\mathrm{BH}$, conforme descrito por LOBATO et al (2007). No entanto, como observado por CHERNICARO et al (1999), a utilização de vertedores triangulares traz como inconveniente a necessidade de cuidados especiais no nivelamento. Fica claro nesta discussão, conforme citado por POPPER, que estabelecida a solução para um determinado problema, aparecem novos problemas. GOMES et al (2007) também cita a necessidade de se realizar limpezas nos vertedores. No dilema da escolha entre tubulação perfurada e vertedores triangulares na área de decantação, nos parece mais conveniente a escolha do vertedores triangulares de forma a se lidar somente com o problema de limpeza de vertedores e eliminar o problema da escuma na área de decantação. Já em relação à resolução do problema de acumulação de escuma no separador trifásico as alternativas de resolução são mais complexas de se projetar e operar.Nas diversas visitas realizadas a diferentes UASBs, constatou-se um sistema que atendeu as nossas expectativas. A ETE de Matão/SP (CAEMA- Companhia de Águas e Esgotos de Matão, CMS Companhia Matonense de Saneamento) utiliza um sistema de comporta na área debaixo das campânulas de gás, conforme figuras 22, 23 e 24. Também há um sistema de jato de água para quebra de escuma em cima das campânulas de gás de modo a permitir o fluxo de gás.Na ETE Ribeirão Pires, este mecanismo de jato de água se mostrou satisfatório na manutenção da pressão no interior das campânulas, que era um indicativo da produção de gás e a não ocorrência de aprisionamento de gás, sendo que a única crítica é que utilizava água potável para realizar esta operação. 


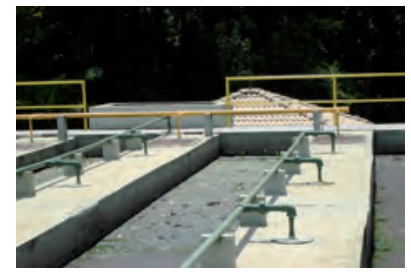

Figura 22: Sistema de jatos de água em cima das campânulas de gás do UASB de Matão

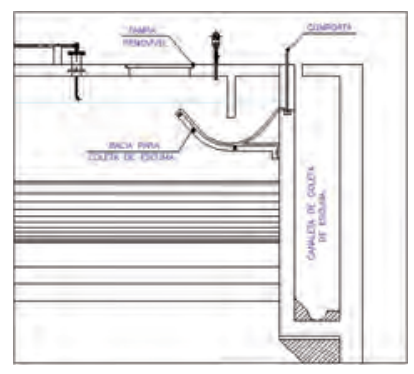

Figura 24: Desenhos do sistema de comporta para remoção de escuma do UASB de Matão. Fonte: Valmir Perruso (Proesa Engenharia) e Kouji Kitahara

Outro sistema de remoção interessante de remoção de escuma é apresentado por CHERNICARO et al (2009), referente a um dispositivo instalado na ETE Onça.

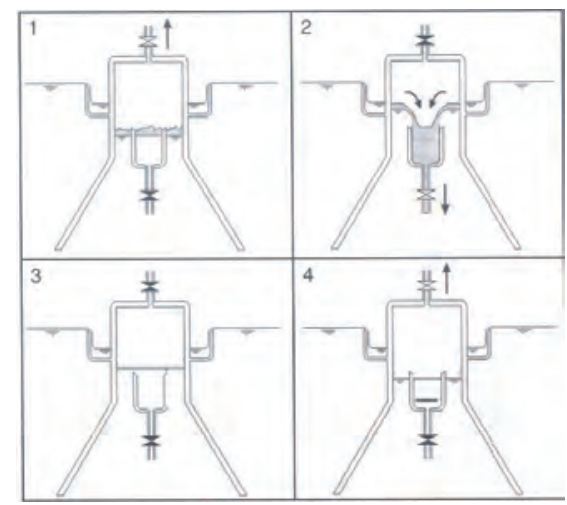

Figura 25: Dispositivo de re moção de escuma do UASB da ETE Onça/MG. Fonte: CHERNICARO et al (2009)

Níveis de escuma (dentro do separador trifásico) e de líquido (superfície do compartimento de decantação) nas condições normais do reator em operação. A válvula de escuma está fechada e a válvula de biogás aberta, sendo que a pressão de gás seja suficiente para manter o nível da escuma cerca de $5 \mathrm{~cm}$ abaixo do vertedor de saída.Redução da pressão de gás, resultando na subida de nível da escuma dentro do separador trifásico. A válvula de biogás é fechada e a válvula de biogás aberta, permitindo que a escuma escoe para os vertedores internos. Final do procedimento de remoção de escuma e fechamento da válvula de escuma.Abertura da válvula de biogás e aumento da pressão, resultando no decréscimo do nível da escuma dentro do separador trifásico. Retorno à condição ordinária do reator em operação. Este dispositivo da ETE Onça possui uma concepção que permite uma remoção de escuma, desde que não ocorra uma solidificação desta escuma. As figuras 26 e 27 ilustram certos detalhes da instalação feita na ETE Onça.

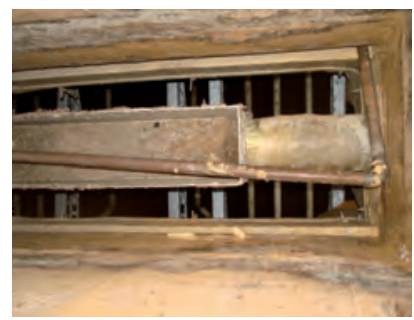

Figura 26:

Calha de remoção de escuma da ETE Onça/

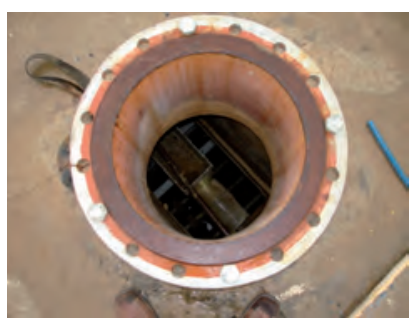

Figura 27: Abertura de inspeção do dispositivo de remoção de escuma da ETE Onça/MG

Tanto o sistema de comporta como o sistema de calha realizam de forma satisfatória a operação de remoção de escuma. No entanto a operação prática de um sistema destes em ETEs de grande porte é dificultada pelo grande número de válvulas e comportas a serem acionadas. Como estes dispositivos localizam-se debaixo das campânulas de gás fica difícil checar se houve ou não a realização da operação.Uma vantagem operacional do sistema de remoção de escuma por comporta/ETE Matão em relação ao sistema de calha coletora é a não necessidade de se aguardar o tempo de subida do nível de líquido no interior do UASB.

O problema da escuma ainda tem campo para a proposição de soluções. Já se pensou, por exemplo, na utilização de tulipas vertedoras para a remoção de escuma nas áreas debaixo das campânulas, no entanto a área de abrangência ficava restrita somente à área adjacente. Outra forma de se operar a remoção de escuma do dispositivo da ETE Onça poderia ser de forma contínua, o que poderia diminuir a ocorrência de zonas mortas, conforme identificada por PEÑA et al (2006), que realizaram um estudo hidrodinâmico em escala real para UASB com volume de $275 \mathrm{~m}^{3}$ e tempo de detenção hidráulico de 7,1 h para a vazão média.

Este artigo relatou a existência de uma grande zona morta debaixo do separador trifásico, bem como curto-circuitos, que surgiam tanto nas condições de sub-vazão como de super-vazão média de projeto. No entanto a imposição de uma lâmina, mesmo que baixa, ao longo de toda a campânula implicaria numa vazão significativamente alta, o que levaria a posteriores problemas nas unidades subseqüentes. O desafio de engenharia seria elaborar um dispositivo de remoção de escuma fácil de ser operado e que não trouxesse problemas de geração de odor. Ou ainda, poderia ser introduzido na área de acúmulo de escuma algum produto que degradasse ou oxidasse esta camada, num custo acessível.

\section{Área de Decantação aberta ou fechada}

Os projetos de UASBs podem optar concepções com área de decantação fechada ou aberta. A ETE de Bucaramanga/Colômbia inicialmente adotou a decantação do tipo aberta, conforme ilustrado na Figura 28.

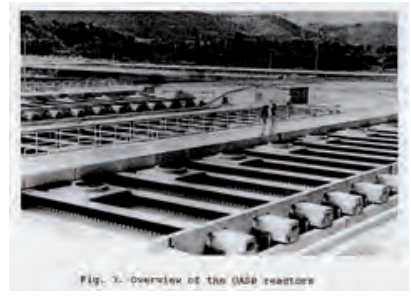

Figura 28: UASB de Bucaramanga. Fonte:

SCHELLINKHOUT, COLLAZOS (1992)

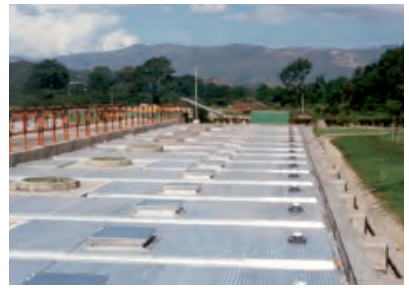

Figura 29: UASB de Bucaramanga coberto com telha de alumínio. Fonte: GIRALDI (2007) 


\section{práticas operacionais e de empreendimentos}

Posteriormente devido a reclamações da vizinhança local, foi feito a cobertura com telhas de alumínio, conforme ilustrado na figura 29.Caminho inverso foi percorrido pela ETE Piçarrão, onde inicialmente estavam instalados telhas na área de decantação, conforme figura 30 e sistema de exaustão de ar. Conforme relato operacional da ETE Piçarrão, devido à necessidade de constantes operações de ajuste das calhas e a não constatação de odores quando descobertos, resolveuse tirar de forma permanente estas telhas de cobertura facilitando a observação visual e manutenção. O odor na ETE Piçarrão é gerado em outros pontos e devidamente tratado.

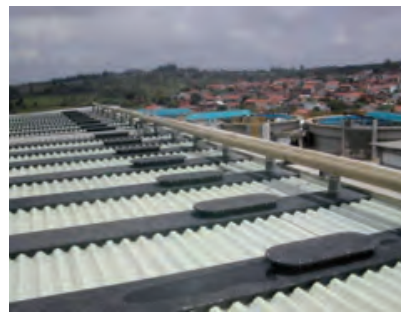

Figura 30:

UASB coberto da ETE Piçarrão. - Fonte: GIRALDI (2007)

Esta facilidade de observação da qualidade do efluente do UASB também deve ser levada em conta quando se faz a cobertura da área de decantação. Na ETE Anhumas, toda a área superior é recoberta, inclusive a área de decantação, conforme figura 31. No entanto não há pontos de coleta de amostra de efluente de cada reator, prejudicando o controle operacional e também a correlação de dados de concentração de sólidos do manto de lodo e sólidos sedimentáveis do efluente.

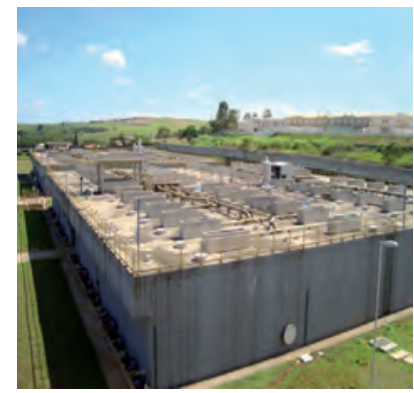

Figura 31:

ETE Anhumas/Campinas com recobrimento total

Tendo em vista esta deficiência, a área de operação da ETE Anhumas está instalando um sistema de tubulações que permita a retirada de amostras de cada reator e assim realizar correlações entre os sólidos sedimentáveis do efluente e a concentração de sólidos do lodo no manto, cujo sistema de amostragem foi devidamente previsto conforme figura 32. Apesar de ser um tanto óbvia esta necessidade de se visualizar a qualidade de efluente final de cada reator UASB, foi mais um pequeno detalhe desprezado na etapa de projeto.

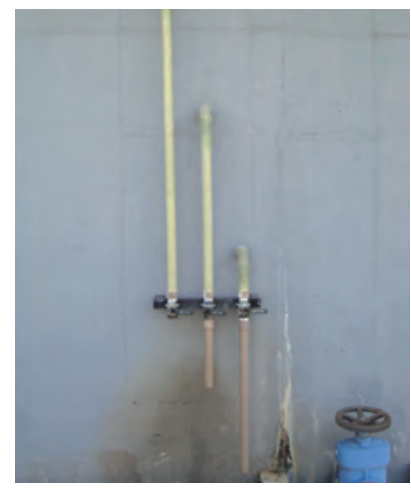

de amostra de lodo em diferentes alturas da ETE Anhumas/ Campinas

A adoção da decantação recoberta pode levar a outras abordagens, mas que caberiam ser avaliadas de forma a comprovar ou não a sua eficácia. Quando se usa a decantação recoberta pode-se igualar a pressão interna da área de decantação como da área debaixo do separador trifásico, que foi a concepção adotada pela ETE Anhumas. Neste tipo de concepção, o efluente antes de sair do UASB fica previamente submetido a uma pressão acima da atmosférica, o que poderia levar a uma maior dissolução do gás metano. Somente medições deste metano poderiam confirmar uma concentração maior ou não que a encontrada por SOUZA et al (2009) de $21 \mathrm{mg} / \mathrm{L}$. Uma possibilidade na adoção da decantação recoberta é aproveitar e impor uma queda significativa do efluente no vertedor de forma a promover uma maior agitação e desprendimento de gases como $\mathrm{H}_{2} \mathrm{~S}$ e metano. No entanto, não se sabe se o este grau de agitação com a pressão no interior no UASB seria suficiente para ajudar a desprender estes gases. Também não se sabe se esta agitação favoreceria a formação de espumas.

\begin{tabular}{|l|l|}
\hline lilema: Opção de área de decantação aberta ou recoberta \\
\hline berta & Coberta \\
\hline ossibilidade de se ter problemas de & Minimização de problemas de odores. \\
dores. & $\begin{array}{l}\text { Necessidade de sistema de exaustão e } \\
\text { tratamento de odores. }\end{array}$ \\
Telhores condições de acesso para & $\begin{array}{l}\text { Necessidade de se prever pontos de coleta } \\
\text { de a mostra do efluente de modo a se } \\
\text { lanutenção e limpeza. }\end{array}$ \\
$\begin{array}{l}\text { Telhores condições de se checar a } \\
\text { ualidade do efluente final em relação à }\end{array}$ & \begin{tabular}{l} 
cherda de sólidos. \\
\hline
\end{tabular}
\end{tabular}

\section{Sistema de medição de gás}

Em diversos UASBs foram instalados medidores de vazão de gás do tipo turbina, com partes móveis. Na grande maioria das instalações com turbina, este medidor acabou danificado por corrosão.Na realidade a medição de biogás é uma tecnologia já dominada para digestores anaeróbios, no entanto, por apresentar um custo elevado, acabou-se buscando alternativas de medição mais viáveis economicamente, mas que vêm apresentando falhas. Um exemplo de medidor funcional é o da Roots Meter, utilizado nos digestores anaeróbios da ETE Franca.
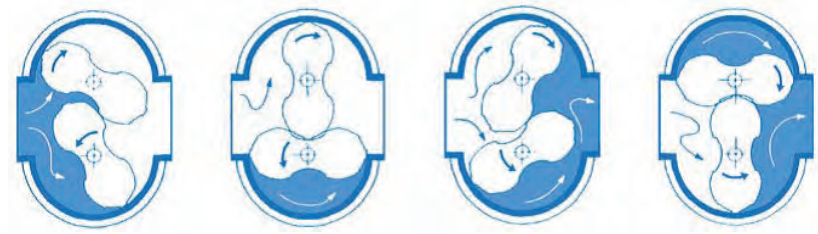

Figura 33: Princípio de funcionamento de um medidor de gás rotativo $e$ de deslocamento positivo. Fonte: Catálogo da Dresser

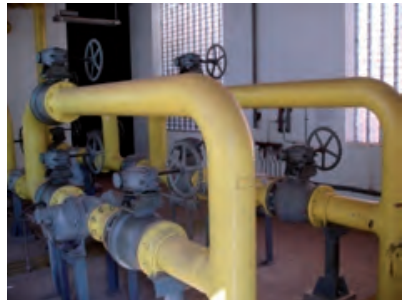

Figura 34: Medidores de gás dos digestores anaeróbios da ETE Franca/São Paulo

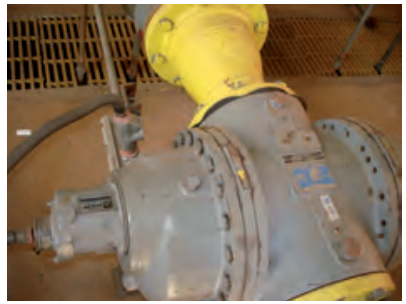

Figura 35: Detalhe do medidor de gás dos digestores anaeróbios da ETE Franca/São Paulo
De forma a buscar alternativas mais econômicas, encontra-se em estágio de testes a utilização de medidores mássicos do tipo térmico para biogás de UASB. 


\begin{tabular}{|l|l|}
\hline Dilema: Medição de biogás \\
\hline Convencionais & Alternativos \\
\hline Alto custo dos medidores convencionais. & Muitas microturbinas instaladas \\
$\begin{array}{l}\text { Por se tratar de gás, necessidade de se } \\
\text { monitorar também a temperatura e }\end{array}$ & apresentaram problemas de corrosão. \\
pressão. & $\begin{array}{l}\text { Medidores mássicos em estágio de } \\
\text { avaliação; }\end{array}$ \\
\hline
\end{tabular}

Em várias publicações nacionais encontra-se certa ênfase na importância da medição e totalização do biogás gerado em UASB. Cabe ser ressaltado que a medição isolada de volume de gás deve ser acompanhada da medição de temperatura e pressão, por se tratar de um fluido compressível, de modo a se ter uma coerência técnica. Esta mesma preocupação com medição do gás deveria ser reforçada para a medição do esgoto afluente a ETEs, que muitas vezes possuem sua capacidade de tratamento estimada apenas em função do número de ligações de água. É comum encontrar instalações de medição com calha parshall, onde não se respeitaram as distâncias dos pontos de interferência, tornando o dado de vazão cheio de imprecisão. Esta constatação também foi relatada em várias ETEs do Canadá, conforme ENVIRONMENT CANADA (2006).

\section{Geração de gases residuais e perda de metano}

Há um ditado que popular que diz que o "diabo está nos detalhes" e que significa que certos detalhes quando são desprezados, trazem posteriormente sérios problemas.A tecnologia UASB traz consigo as vantagens fundamentadas de menor produção de lodo e gasto energético, mas traz também certas coisas pequenas e de efeitos bem devastadores, caso não sejam devidamente encaminhadas. É o caso da escuma citada anteriormente que acumula ao longo do tempo e se solidifica debaixo da campânula de gás. Também é o caso do gás sulfídrico, $\mathrm{H}_{2} \mathrm{~S}$, principal agente responsável pelos maus odores e também responsável por problemas de corrosão. E finalmente é o caso dos siloxanos, a ser discutido mais a frente.Em muitos UASBs já construídos há pontos de queda do efluente que apresentam altas concentrações de $\mathrm{H}_{2} \mathrm{~S}$ e muitas vezes não são previstas estruturas cobertas para a captação e tratamento destes gases.Há também a presença de gás metano que não é capturada pela campânula e que se encontra dissolvida na massa líquida do efluente do UASB, que segundo SOUZA et al (2009) podem apresentar uma concentração de $21 \mathrm{mg} / \mathrm{L}$ (condição de supersaturação). Este metano dissolvido acaba sendo lançado na atmosfera nas unidades posteriores, como por exemplo, num tanque de aeração de um sistema de lodos ativados. Ainda, de acordo com SOUZA et a (2009), a perda de metano no efluente líquido correspondeu a 44,8\% da produção total de gás gerado (dissolvido + biogás).A presença do $\mathrm{H}_{2} \mathrm{~S}$ e de significativa parcela do metano produzido no efluente de um UASB leva ao seguinte dilema: o que fazer com estes gases após o seu desprendimento? Sabe-se que os sistemas de remoção de odor atuam sobre $\mathrm{o}_{2} \mathrm{~S}$ e não sobre o metano. Surge então o seguinte problema: este fluxo de gases residuais com metano concentrados num ponto de tratamento de odor não poderiam colocar em risco a segurança? Desta forma, caso haja um sistema de exaustão para o recolhimento de gases gerados numa estrutura de dissipação ou "stripping”, faz-se necessário, além do tratamento dos odores, um adequado direcionamento deste gás metano. Uma abordagem é assumir uma alta emissão de metano através da emissão para atmosfera. Ou então, realizar a devida concentração do gás metano para posterior tratamento ou queima. Caso o tratamento seja do tipo lodos ativados, o próprio tanque de aeração possuiria uma ação inibidora de odor do $\mathrm{H}_{2} \mathrm{~S}$ presente. Este tipo de concepção é o encontrado na ETE Matão, onde após o UASB, não há a ocorrência de pontos de turbulência entre o UASB e o tanque de aeração. No entanto o metano dissolvido no efluente acaba sendo emitido para a atmosfera.

Atualmente a comunidade técnica lembra-se com ironia dos projetos antigos de ETEs, onde a questão do lodo era tratada com a ilustração de um caminhão e uma seta com legenda de "vai para disposição final".

Tendo em vista a preocupação cada vez mais alarmante de emissão de gases de efeito estufa, não poderíamos prever que seremos objetos de ironias futuras ao afirmarmos que o gás metano gerado num tratamento anaeróbio era simplesmente lançado na atmosfera?Como demanda tecnológica, cabe desenvolver um sistema que retire o metano dissolvido do efluente de UASB e seu posterior tratamento.Além da questão do odor e do metano, cabe ressaltar a necessidade de se prevenir as estruturas em contato com estes gases residuais de forma a se prevenir problemas de corrosão. Na ETE Matão os reatores UASB tiveram parte das paredes e tetos tratados com resina à base de óleo de mamona, de forma a se proteger contra a corrosão do concreto.

\begin{tabular}{|l|l|}
\hline Dilema: Tratamento ou não dos Gases Residuais \\
\hline Tratamento dos gases residuais & Não tratamento dos gases residuais \\
\hline Previsão de estruturas de dissipação de & Caso não seja previsto sistema de tratamento de \\
energia para o efluente do UASB e com & gases residuais, o efluente após a saída do UASB \\
sistema de tratamento de gases. & deve sofrer a mínima perturbação possivel até \\
O metano não é passível de ser tratado nos & atingir a unidade posterior. \\
sistemas convencionais de tratamento de & O metano dissolvido no efluente sairá na unidade \\
odores, devendo ser devidamente & posterior, contribuindo para o efeito estufa. \\
concentrado e tratado de forma específica. & $\begin{array}{l}\text { Para diminuir a concentração do metano no } \\
\text { efluente final recomenda -se uma estrutura de } \\
\text { dissipação de energ ia após a saída dos vertedores } \\
\text { triangulares e dentro do próprio UASB de forma a } \\
\text { ser a coletado nas campânulas. }\end{array}$ \\
\hline
\end{tabular}

\section{Biogás}

$\mathrm{Na}$ maioria das ETEs do Brasil, o biogás gerado num processo anaeróbio é muitas vezes encaminhado para queimadores do tipo aberto. Há alguns anos vêm surgindo questões na emissão dos gases de efeito estufa, créditos de carbono, energia "verde" e sustentabilidade e conseqüentemente pressões para a realização de reaproveitamento energético deste biogás.

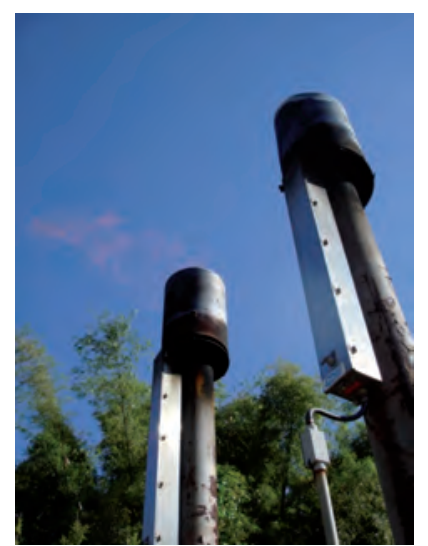

Figura 36:

Queimador de biogás de digestor anaeróbio da ETE Franca

Mesmo nos EUA, menos que $20 \%$ das ETEs convertem o biogás em energia ou calor, conforme MONTEIGH et al (2007) apud US EPA (2007). Quando se propõe soluções de reaproveitamento deste biogás ao invés da simples queima parcial, deve ser lembrado que o biogás contém outros compostos que não tão somente o metano. Um caso é relatado na ETE Hyperion de Los Angeles por LEWIS et al (2008) que se confrontou com um misterioso pó branco, conforme descrito pela área operacional, e que se depositava principalmente na caldeira.

Após uma investigação mais apurada, identificaram-se, como a origem daqueles depósitos, os siloxanos do biogás, ou ainda, também conhecidos como siloxinas conforme VELÁZQUEZ et al 


\section{práticas operacionais e de empreendimentos}

(2003) .Os siloxanos são encontrados normalmente em produtos de cosméticos para cabelo e pele, desodorantes, detergentes, pasta de dente, etc. Na combustão do siloxanos são formados depósitos de sílica $\left(\mathrm{SiO}_{2}\right)$ de cor branca e que ficam aderidos nos equipamento de câmaras de combustão, turbinas, pistões, caldeiras, etc.Os siloxanos vêm recebendo cada vez mais atenção principalmente devido aos problemas em escala real na operação das ETEs, sendo citado entre outros por MIGNONE (2008) e PARRY (2008).Entre os métodos utilizados de remoção de siloxanos do biogás, pode-se citar o abaixamento de temperatura no ponto de condensação de -23 a $-29^{\circ} \mathrm{C}$ utilizado pela ETE de Baltimore, conforme SCHROEDEL (2009) e o carvão ativado utilizado pela ETE Hyperion de Los Angeles, conforme LEWIS et al (2008).Para o reaproveitamento energético do gás, além da purificação, necessita-se a instalação de um reservatório de armazenamento de modo a equalizar a vazão produzida. E a avaliação técnico- econômica deve levar em conta que parte do metano produzido é perdida no efluente de forma dissolvida, atingindo valores da ordem de 50\% conforme SOUZA et al (2009), caso não seja devidamente concentrada.

\begin{tabular}{|l|l|}
\hline Dilema: Aproveitamento energético ou não do Biogás \\
\hline $\begin{array}{l}\text { Não aproveitamento energético do } \\
\text { biogás }\end{array}$ & Aproveitamento energético do biogás \\
\hline $\begin{array}{l}\text { Recomendada a queima total do biogás ao } \\
\text { invés da queima parcial, que possui um } \\
\text { custo mais alto. }\end{array}$ & $\begin{array}{l}\text { Necessidade de se ter um reservatório de } \\
\text { gás. } \\
\begin{array}{l}\text { Na queima parcial com chama aberta, } \\
\text { considera-se emissão parcial de gás } \\
\text { metano para atmosfera. }\end{array}\end{array}$ \\
$\begin{array}{l}\text { para remoção de umidade, } \mathrm{H} \quad{ }_{2} \mathrm{~S}, \mathrm{CO}_{2} \text { e } \\
\text { siloxanos. }\end{array}$ \\
\hline
\end{tabular}

\section{Outras configurações de Reatores Anaeróbios}

Outra forma de se enfrentar os diversos problemas referentes ao UASB seria a busca de outra configuração de processo anaeróbio. Um tipo de configuração que tem sido bem estudado em escala laboratorial são os reatores anaeróbios em batelada seqüenciais, com biomassa granular (ASBR - Anaerobic Sequencing Batch Reactor) ou imobilizada (ASBBR - Anaerobic Sequencing Batch Biofilm Reactor ), conforme descrito por LAPA (2006). NOVAES (2008) estudou a influência da mistura na agitação de reatores ASBR e ASBBR em escala piloto (reatores com volume útil de $1,02 \mathrm{~m}^{3}$ ) tratando esgoto sanitário. Foi obtida a devida formação de grânulos em reatores ASBR para intensidade de 40 rpm. Já em $80 \mathrm{rpm}$ houve a ruptura dos grânulos e formação de uma escuma na parte superior. É interessante relatar a experiência prática da adoção dos reatores aeróbios em batelada, de forma a prevenir novas concepções problemáticas na etapa de projeto. Na SABESP, a grande maioria das ETEs implantadas no Litoral do Estado de São Paulo é do tipo de lodo ativado por batelada e uma falha encontrada nos projetos mais antigos, refere-se ao dispositivo de coleta do efluente após a sedimentação, que foi concebido através de flutuadores com lâmina constante de saída do efluente, de forma a proporcionar a mesma vazão de descarte. Logo no início da etapa de descarte do efluente, a tubulação de descarga de efluente estava contaminada com sólidos que entravam na etapa de mistura, devido à falta de um bloqueio. Desta forma, o início do descarte de efluente ficava sempre carregado de sólidos, prejudicando a qualidade do efluente final. Os projetos atuais das ETEs do Litoral de São Paulo previram um dispositivo de bloqueio através de pistão, impedindo assim a entrada de sólidos na tubulação de descarte de efluente na etapa de mistura. Outro problema encontrado nos antigos reatores em batelada é a falta de automação relativa à abertura e fechamento de válvulas. Muitas destas ETEs instaladas estão em ritmo lento de automação devido à limitação de recursos financeiros, prejudicando assim a operação. Esta preocupação de automação em sistemas por batelada foi relatada nas reuniões da revisão da norma NBR 12209 - Elaboração de Projetos HidráulicoSanitários de Estações de Tratamento de Esgotos Sanitários e provavelmente será incorporada.Outra forma configuração de processo interessante de ser investigada é a variante do processo de batelada por decantação alternada, onde o descarte do efluente é contínuo e não são necessários dispositivos complexos de saída do efluente. No caso da decantação alternada também merece cuidado a contaminação do efluente no canal de saída durante a etapa de mistura, devendo ser previsto um sistema de limpeza no canal ou retorno do efluente. Todas estas dificuldades técnicas citadas nos reatores aeróbios devem ser devidamente estudadas quando transportadas para reatores anaeróbios, com o agravante de que os anaeróbios devem ser cobertos para a captação de biogás. Em suma, como novos problemas da aplicação de reatores anaeróbios seqüenciais podem ser citados a dificuldade de acesso e visualização, problemas relacionados à corrosão dos impelidores e problemas de descarte inicial do efluente final devido à contaminação de sólidos.

\section{UASB após lodos ativados}

No Brasil, a adoção isolada do UASB como tratamento de esgotos não apresenta viabilidade do ponto de vista legal.Desta forma, torna-se preciso a adoção de alguma forma de pós-tratamento, sendo o lodo ativado uma modalidade que atende as expectativas de tratamento de nível secundário.

\section{Abordagem geral de projeto}

Em projeto de ETE o parâmetro de idade de lodo é estabelecido inicialmente, de forma a ter ou não nitrificação ou de se ter ou não um lodo estabilizado de forma aeróbia.Caso não haja a necessidade de nitrificação, os principais parâmetros sugeridos de projeto de póstratamento de efluente de UASB estão apresentados na tabela 2.

\begin{tabular}{|l|l|}
\hline Parâmetro & Valor \\
\hline Idade do lodo (d) & 6 a 10 \\
\hline $\begin{array}{l}\text { Relação A/M (kg } \\
\text { DBO/kgSSVTA.d) }\end{array}$ & 0,25 a 0,40 \\
\hline $\begin{array}{l}\text { Tempo de detenção hidráulica } \\
\text { (h) }\end{array}$ & 3 a 5 \\
\hline Concentração de SSVTA (mg/L) & 1100 a 1500 \\
\hline Concentração de SSTA (mg/L) & 1500 a 2000 \\
\hline Relação SSV/SS no reator & 0,75 a 0,77 \\
\hline
\end{tabular}

Tabela 2:

Parâmetros de tanque de aeração em sistema de lodos ativados como pós-tratamento de efluentes de reatores anaeróbios (esgotos domésticos)

\section{Fonte:}

SPERLING, M, V.; VAN HAANDEL, A. C.; JORDÃO. E.P.; CAMPOS, J. R.; CYBIS, L.F.; AISSE, M.M.; ALEM SOBRINHO, P. (2001)

Para este tipo de concepção, o lodo aeróbio excedente seria direcionado para o UASB, onde sofreria um adensamento e digestão. De acordo com METCALF \& EDDY (2003), a nitrificação é a oxidação biológica da amônia que ocorre em 2 etapas, sendo que na primeira etapa a amônia $\left(\mathrm{NH}_{4}-\mathrm{N}\right)$ é oxidada em nitrito $\left(\mathrm{NO}_{2}-\mathrm{N}\right)$ e em seguida o nitrito é oxidado em nitrato $\left(\mathrm{NO}_{3}-\mathrm{N}\right)$. De acordo com VAN HAANDEL et al (1982) a idade do lodo mínima para nitrificação é estimada por:

$$
R_{S, N, M I N}=\frac{1}{\left[\mu_{N, M, T}\left(1-f_{X, T}\right)-b_{N, T}\right]}
$$


Onde:

$\mu_{\mathrm{N}, \mathrm{M}, \mathrm{T}}=$ taxa específica máxima de crescimento de Nitrossomonas $\left(\mathrm{d}^{-1}\right)$ $\mu_{\mathrm{N}, \mathrm{M}, \mathrm{T}}=\mu_{, \mathrm{M}, 20^{\circ} \mathrm{C}} \times \theta^{\mathrm{T}-20}$

MARAIS, EKAMA (1976) apud VAN HAANDEL, MARAIS (1999) citam os valores de $\mu_{,{ }_{\mathrm{M}, 20^{\circ} \mathrm{C}}}=0,33$ a 0,65 e $\theta=1,123$, resultando em:

$\mu_{\mathrm{N}, \mathrm{M}, \mathrm{T}}=0,33 \times 1,123^{\mathrm{T}-20}$

Sendo a T a temperatura crítica nas condições de inverno

$\mathrm{b}_{\mathrm{N}, \mathrm{T}}=$ coeficiente de respiração endógena das nitrificantes $\left(\mathrm{d}^{-1}\right)$

$\mathrm{b}_{\mathrm{N}, \mathrm{T}}=0,04 \times(1,029)^{\mathrm{T}-20}$

$\mathrm{f}_{\mathrm{X}, \mathrm{T}}=$ fração anóxica da biomassa

$\mathrm{f}_{\mathrm{X}, \mathrm{T}}=0$, quando o sistema não for projetado para desnitrificação

$\mathrm{f}_{\mathrm{X}, \mathrm{T}}=$ que poder ser assumido inicialmente em $30 \%$ (que seria a $\%$ do reator anóxico do volume total de reator biológico)

METCALF \& EDDY (2003) recomenda a utilização de um fator de segurança para aumentar esta idade do lodo mínima para nitrificação, de modo a permitir uma maior flexibilidade operacional em controlar a idade do lodo e providenciar às bactérias nitrificantes a capacidade de assimilar cargas de pico de NKT. Este fator de pico pode variar de 1,3 a 1,5, dependendo do tamanho da ETE. E caso a opção de projeta seja a estabilização aeróbia do lodo, também denominada como aeração prolongada, adota-se uma idade do lodo igual ou superior a 20 dias. Para esta idade do lodo normalmente já ocorre a nitrificação. Esta idade do lodo é suficientemente longa, de modo que o lodo de descarte pode ser adensado e encaminhado diretamente para o desaguamento. Estabelecida a Idade do Lodo, calcula-se a massa de lodo do sistema, que pode ser feita conforme o modelo cinético de Marais e colaboradores.

\section{Lodo Heterotrófico}

O lodo heterófico é a somatória do lodo ativo, lodo endógeno, inertes e é dada por:

$M X_{V H}=Q S i\left[\frac{\left(1-f_{U S} \mid f_{U P}\right) Y_{H} R_{S}}{\left(1+b_{\boldsymbol{h} T} R_{S}\right)}\left(1+f b_{\boldsymbol{h} T} R_{S}\right)+R_{S} \frac{f_{u p}}{P_{v}}\right]$

$\mathrm{MX}_{\mathrm{VH}}=$ Massa de SSV no reator biológico (kg SSVTA)

$\mathrm{Q}=$ vazão afluente $\left(\mathrm{m}^{3} / \mathrm{dia}\right)$

$\mathrm{S}_{\mathrm{i}}=$ concentração da DQO afluente $\left(\mathrm{kg} / \mathrm{m}^{3}\right)$

$\mathrm{f}_{\mathrm{US}}=$ fração da DQO solúvel não biodegradável

$\mathrm{f}_{U P}=$ fração da DQO particulada não biodegradável

$\mathrm{Y}_{\mathrm{h}}=$ coeficiente de síntese celular $=0,45 \mathrm{~kg} \mathrm{SSV}$ produzido $/ \mathrm{kg}$ $\mathrm{DQO}_{\text {removida }}$

$\mathrm{b}_{\mathrm{hT}}=$ coeficiente de respiração endógena

$\mathrm{b}_{\mathrm{hT}}=0,24 \times 1,04^{(\mathrm{T}-20)}$

$\mathrm{P}_{\mathrm{v}}=$ razão DQO $/ \mathrm{SVS}$ em lodo orgânico $=1,50 \mathrm{~kg}$ DQO $/ \mathrm{kg} \mathrm{SVS}$
Os valores das frações orgânicas de efluentes de reatores UASB foram determinados por BRITO (2006) e citados na tabela 3.

\begin{tabular}{|l|l|}
\hline Fração & Efluente de UASB \\
\hline $\mathrm{f}_{\mathrm{rb}}$ & 0 \\
\hline $\mathrm{f}_{\mathrm{US}}$ & $0,15 \mathrm{a} 0,20$ \\
\hline $\mathrm{f}_{\mathrm{UP}}$ & 0,15 \\
\hline $\mathrm{f}_{\mathrm{b}}$ & 0,65 \\
\hline
\end{tabular}

Tabela 3: Valores das frações de DQO para esgotos tipicamente domésticos e os encontrados para o efluente de $U A S B$

Onde:

$\mathrm{f}_{\mathrm{rb}}$ : fração da concentração de substrato total afluente expressa em DQO que é rapidamente biodegradável

$\mathrm{f}_{\mathrm{b}}$ : fração da concentração de substrato total afluente expressa em DQO biodegradável e particulada

De forma a checar estas frações orgânicas, utilizou-se o Modelo Matemático de Marais e colaboradores com os resultados operacionais da ETE de Matão e estão apresentados a seguir. Com estes valores determinaram-se os valores de SST e SSV do tanque de aeração.

Dados da ETE Matão:

Período: mês de dezembro de 2008

Temperatura média: $30,1^{\circ} \mathrm{C}$

$Q$ média $=13.006 \mathrm{~m} 3 / \mathrm{d}(150 \mathrm{~L} / \mathrm{s})$

DQO de entrada nos UASBs: $549 \mathrm{mg} / \mathrm{L}$

DQO de saída dos UASBs (media de 2 reatores): $123 \mathrm{mg} / \mathrm{L}$

NKT de saída nos UASBs: $15 \mathrm{mg} / \mathrm{L}$

OD no Tanque de aeração: $1,1 \mathrm{mg} / \mathrm{L}$

Idade do Lodo: 12 dias;

Vazão de reciclo do lodo: $8457 \mathrm{~m} 3 / \mathrm{d}$

Volume total dos Tanques de Aeração (2 unidades): $5040 \mathrm{~m} 3$

fUS: 0,15

fUP: 0,15

\begin{tabular}{|l|l|l|}
\hline Parâmetro & $\begin{array}{l}\text { Modelo } \\
\text { Marais }\end{array}$ & $\begin{array}{l}\text { Resultado } \\
\text { operacional }\end{array}$ \\
\hline SST $(\mathrm{mg} / \mathrm{L})$ & 1035 & 1069 \\
\hline SSV $(\mathrm{mg} / \mathrm{L})$ & 859 & 841 \\
\hline
\end{tabular}

Tabela 4: Comparativo de valores de SST e SSV no Tanque de Aeração entre Modelo matemático e resultados operacionais da ETE Matão/SP. Ou seja, os parâmetros de fus e fup determinados por BRITO (2006) estão coerentes com os valores encontrados na prática operacional de uma ETE em escala real. 


\section{Lodo Autotrófico}

MXN = Massa de bactérias nitrifcantes em SSV no reator biológico (kg SSVTA)

$\mathrm{YN}=0,10-$ coeficiente de síntese celular das nitrificadoras $(\mathrm{kg}$ $\mathrm{SSV} / \mathrm{kg} \mathrm{N}$ )

NDISP = carga de $\mathrm{N}$ disponível para nitrificação $(\mathrm{kg} \mathrm{N} /$ dia $)$

$\mathrm{NDISP}=\mathrm{N}-\mathrm{NKT}$ afluente $-0,1 \times \Delta \mathrm{XVH}$

$\mathrm{N}-\mathrm{NKT}$ afluente $=$ carga afluente de $\mathrm{N}$

$\Delta \mathrm{XVH}=$ excesso de lodos ativados

$\Delta \mathrm{XVH}=\mathrm{MXVH} / \mathrm{RS}(\mathrm{kg} \mathrm{SSV} / \mathrm{dia})$

Em termos relativos, a massa de nitrificantes é bem menor que a massa de lodo heterotrófico.Estabelecida a massa total de lodo (heterotrófica mais autotrófica) determina-se finalmente a o volume do reator biológico em função da adoção de uma concentração de SSVTA.E é justamente neste ponto que merece um cuidado de forma a se calcular o volume final. Procurou-se na bibliografia um valor de SSVTA com idade de lodo correspondente para nitrificação e não se encontrou de forma explícita um valor de recomendação. Já nos defrontamos com propostas de projeto de UASB e lodos ativados com SST de 4500 a $5000 \mathrm{mg} / \mathrm{L}$ e que por segurança, não foram aceitas devido a falta de dados operacionais que comprovassem estes valores, ou ainda, estudos em escala piloto que permitissem esta adoção. JORDÃO et al (2009) citaram o caso da ETE Itaipu em Niterói $(70 \mathrm{~L} / \mathrm{s})$ com nitrificação e desnitrificação, onde se relata uma operação com SST de $2700 \mathrm{mg} / \mathrm{L}$. Em fase de projeto, encontra-se a ETE de São José do Rio Preto, com desnitrificação parcial e desvio de $25 \%$ no UASB para o tanque de aeração, com um valor adotado de $2,2 \mathrm{~kg} / \mathrm{m} 3$ de SSV e idade do lodo de 12 dias.Resta saber se concentrações elevadas de SST no tanque de aeração e conseqüentemente com volume e tempos de detenção menores levariam a condições de estabilidade do sistema. E caso seja, de fato, possível a manutenção de concentrações elevadas de SST no tanque de aeração, o fator limitante a ser investigado seria a etapa posterior de clarificação. Por exemplo, um campo que está sendo investigado recentemente é a utilização de decantação lamelar após sistemas de lodos ativados.

\section{Descarte de excesso de lodo}

Em consulta a diversos projetistas, encontram-se diferentes posições a respeito do excesso de lodo do UASB. Alguns defendem que o descarte de lodo ativado poderia ser encaminhado para o UASB, que serviria como adensador e digestor deste lodo. Investigações realizadas por CASEIRO et al (2007) mostraram que viabilidade de fazer o tratamento do lodo excedente de um sistema de lodos ativados no UASB.

Outra abordagem defende a segregação deste descarte de lodo para adensamento e posterior mistura com o descarte de lodo do UASB. De acordo com alguns projetistas, este descarte do lodo ativado no UASB pode resultar em eventuais perdas destes sólidos. Ao se fazer esta segregação de excesso de lodo ativado do excesso de lodo do UASB, caso se queira um lodo inteiramente estabilizado deve-se ter uma idade de lodo superior a 18 dias no sistema de lodos ativados. Este lodo aeróbio estabilizado seria então encaminhado para um sistema de adensamento para posterior mistura com o lodo do UASB e finalmente para desaguamento.
Em contato com as áreas operacionais da ETE Matão e Piçarrão, constatou-se que na partida destas ETEs houve uma perda inicial de sólidos no efluente do UASB que recebe o descarte de lodo excedente do sistema de lodos ativados. Após a estabilização da rotina operacional do sistema de tratamento este tipo de problema desapareceu, no entanto recomendam-se novas investigações de campo no monitoramento deste descarte de sólidos do lodo ativado no UASB.

\section{Remoção de nitrogênio}

Quando se utiliza o UASB como a primeira unidade de tratamento, praticamente é consumida toda a DQO rapidamente degradável do afluente. Já em relação ao material nitrogenado, a remoção é praticamente desprezível no tratamento anaeróbio. Quando se almeja a remoção de nitrogênio, a concepção clássica é realizada através da nitrificação, que é a oxidação biológica de amônia, tendo como produto final o nitrato, e a desnitrificação, que é a redução biológica de nitrato para nitrogênio molecular, tendo-se material orgânico como redutor.E uma das condições para que ocorra a desnitrificação é a presença de um doador de elétrons (redutor de nitrato) e que pode ser o próprio material orgânico biodegradável.

Quando há carência deste tipo de material, recorre-se a uma fonte externa como etanol, metanol, acetona e ácido acético.Pode-se recorrer a realização de uma desnitrificação parcial, por exemplo, com efluente final com nitrato de $20 \mathrm{mg} / \mathrm{L}$ de $\mathrm{N}$, através do "bypass" do UASB com 25 a $50 \%$ do esgoto bruto para o sistema de lodos ativados, conforme JORDÃO et al (2009). No entanto quando há um "by-pass" superior a $30 \%$, não haveria mais vantagens econômicas na utilização dos UASBs. Ou seja, quando se utiliza UASB, é desfavorecida a implantação de uma unidade de desnitrificação, de forma realizar a remoção de nitrogênio. $O$ dilema que se lança é saber que os parâmetros de lançamento de efluentes de ETEs estão se tornando cada vez mais restritivos e desta forma a tecnologia UASB não seria capaz de atender a esta tendência. Por outro lado, também há uma pressão para realizar o reuso agrícola, de forma a retornar justamente estes nutrientes, como o nitrogênio ao solo e não ao ar, o que flexibilizaria esta imposição de parâmetros mais restritivos.

\section{CONCLUSÕES}

- a tecnologia UASB tem como um dos grandes atrativos a menor geração de lodo, que é um dos principais itens de custo numa ETE. Outro atrativo seria a geração de gás metano resultante do processo anaeróbio que poderia ser utilizada para outros fins como a cogeração. No entanto, para fazer este aproveitamento energético é necessária a purificação do gás, pois os elementos como siloxanos e gás sulfídrico trazem vários problemas operacionais nas aplicações em escala real. Também devem ser desenvolvidos meios de se retirar o metano dissolvido no efluente do UASB, de modo a não serem posteriormente lançados na atmosfera e aumentar o reaproveitamento.- um dos maiores problemas da tecnologia UASB é a remoção de escuma localizada debaixo das campânulas de gás. Devem ser estudados novos dispositivos para efetuar esta remoção de forma viável para a operação, ou ainda, ser criados novas formas de tratamento deste material no local.- outro problema da tecnologia UASB em instalações de grande porte é a existência de vários pontos de controle. Deve-se prever na etapa de projeto como a operação seria realizada em função dos recursos humanos disponíveis.

- uma das formas de pós-tratamento de UASB é a adoção de lodos ativados. Recomenda-se a realização de investigações de campo 
para checar valores máximos de SST ou SSV no tanque de aeração de modo a reduzir o tamanho desta unidade. Caso estes valores puderem ser altos, recomendam-se estudos com decantação lamelar que recebam a contribuição deste sistema de lodos ativados.

Também se recomenda a investigação de campo da influência do descarte de excesso de lodo no UASB, checando se há ou não perda de sólidos em excesso no efluente do UASB.

\section{REFERÊNCIAS BIBLIOGRÁFICAS}

ALEM SOBRINHO, P.; KATO, M. T. Tratamento de esgotos sanitários por processo anaeróbio e disposição controlada no solo. Capítulo 12, Análise crítica do uso do processo anaeróbio. PROSAB, ABES, Rio de Janeiro, 1999.

BRITO, M.F. Determinação das frações orgânicas de efluentes de reatores UASB. Dissertação de Mestrado apresentada a Escola Politécnica da Universidade de São Paulo, Departamento de Engenharia Hidráulica e Sanitária, 2006.

CAESB. Sinopse do Sistema de Esgotamento Sanitário do Distrito Federal. DEZEMBRO 2008. Disponível em: http://www.caesb.df.gov.br/_conteudo/ siesg/SIESG2008.pdf. Acesso em 15 DEZ 2009.

CASEIRO, A.H.; PIVELI, R.P.; ALEM SOBRINHO, P. Avaliação de desempenho de um digestor anaeróbio de fluxo ascendente e manta de lodo (UASB) tratando esgoto sanitário e digerindo lodo aeróbio excedente. Anais do $24^{\circ}$ Congresso Brasileiro de Engenharia Sanitária e Ambiental, ABES, Belo Horizonte, 2007.

CHERNICARO, C.A.L.; ALMEIDA, P.G.S.; LOBATO, L.C.S.; COUTO, T.C.;

BORGES, J.M.; LACERDA, Y.S. Experience with the design and start up of two full-scale UASB plants in Brazil: enhancements and drawbacks. Water Science \& Technology, 60.2, IWA Publishing, 2009.

CHERNICARO, C.A.L.; VAN HAANDEL, A.; AISSE, M.M.; CAVALCANTI, P.F.F. Capítulo 7, Reatores Anaeróbios de Manta de Lodo. Tratamento de esgotos sanitários por processo anaeróbio e disposição controlada no solo. PROSAB, ABES, Rio de Janeiro, 1999.

ENVIRONMENT CANADA. Guidance manual for sewage treatment plant, process audits. 2006.

FORRESTI, E.; FLORÊNCIO, L.; VAN HAANDEL, A.; ZAIAT, M.; CAVALCANTI, P.F.F. Tratamento de esgotos sanitários por processo anaeróbio e disposição controlada no solo. Capítulo 2, Fundamentos do tratamento anaeróbio. PROSAB, ABES, Rio de Janeiro, 1999.

GIRALDO, E. Anaerobic treatment, Rowan Universitiy, $5^{\text {th }}$ October 2007. Disponível em: http://www.rowan.edu/colleges/engineering/clinics/ engwoborders/Resources/Rowan\%20Conf\%2007/Water-Wastewater/ Anaerobic\%20Treatment.pdf. Acesso em 7 DEZ 2009.

GOMES, C.S.; ALVES, H.B.; SQUIBA, L.M. Escumas como pesadelos dos tratamentos RALF e UASB para esgotos sanitários. Anais do $24^{\circ}$ Congresso Brasileiro de Engenharia Sanitária e Ambiental, ABES, Belo Horizonte, 2007.

GOMES, C.S. Digestores anaeróbios inovadores e eficientes à temperatura ambiente para esgotos domésticos e industriais usando-se "filtros anaeróbios fluidizados". Anais do $11^{\circ}$ Congresso Brasileiro de Engenharia Sanitária e Ambiental, ABES, Fortaleza, 1981.

GOMES, C.S. Módulo de tratamento anaeróbio de esgotos domésticos com processamento de gás para fins automotivos. Anais do $12^{\circ}$ Congresso Brasileiro de Engenharia Sanitária e Ambiental, ABES, Camboriú, 1983.

GRANDIN, S. R. Concepção das estações de tratamento de esgotos do
Recomenda-se a elaboração de projetos com novas concepções de configuração de UASB, ou ainda, novas configurações de reator anaeróbio de modo a sanar os problemas aqui relatados. Um tipo de reator que vem sendo objeto de pesquisa em escala piloto é o tipo batelada. - de forma genérica, conclui-se que a adoção do UASB traz consigo implicações não muito fáceis de serem resolvidas e muitas vezes a resolução de um problema leva a outros problemas.

município de Campinas-SP. 10p. Disponível em <http://www.semasa. sp.gov.br/Documentos/Publicar_Internet/trabalhos/trabalho_81.pdf $>$. Acesso em: 25 NOV. 2009.

GONÇALVES, R.F.; LUDUVICE, M. Capítulo 2 Alternativas de minimização da produção e desaguamento de lodo de esgoto. Impacto Ambiental do Uso Agrícola do Lodo de Esgoto. Editores Wagner Bettiol e Otávio A. Camargo. EMBRAPA, 2000.

JORDÃO, E.P.; VOLSCHAN JR, I.; ALEM SOBRINHO, P. Secondary WWTP preceded by UASB reactors - an excellent Brazilian experience, Water Practice \& Technology, Vol. 14, $\mathrm{n}^{\circ}$ 1, 2009.

KELLER, J.; WALLIS-LAGE, C.; CRABTREE, I. The fine art of screening. Water Environment \& Technology, Vol. 18, n 12, DEC, 2006.

LAPA, K.R. Avaliação da recirculação da fase líquida e do regime de alimentação em reator anaeróbio, em escala piloto, operado em bateladas seqüenciais contendo biomassa imobilizada (ASBBR), aplicado ao tratamento de esgoto sanitário. Tese de Doutorado apresentada na Escola de Engenharia de São Carlos, USP, São Carlos, 2006.

LEWIS, F.M.; HAUG, R.T.; POOSTI, A.; REDD, K.R.; A powerful byproduct. Water Environment \& Technology, p.64-69, Vol. 20, nº 1, JAN, 2008.

LOBATO, L.C.S.; CHERNICARO, C.A.L.; OLIVEIRA FILHO, J.M.; MORAES, O. J.S.; SOUZA, J.R. Avaliação de desempenho da pré-operação dos reatores UASB da ETE Onça: capacidade instalada $2,05 \mathrm{~m}^{3} / \mathrm{s}$. Anais do $24^{\circ}$ Congresso Brasileiro de Engenharia Sanitária e Ambiental, ABES, Belo Horizonte, 2007.

METCALF \& EDDY. Wastewater engineering, treatment and reuse, 4th edition, 2003.

MIGNONE, N. FAD or future? Water Environment \& Technology, Vol. 20, $\mathrm{n}^{\mathrm{o}} 10$, NOV, 2008

MONTEIGH, H.; BAGLEY, D.; KALOGO, Y.; RAMANI, R.; FILLMORE, L.; Power recovery tool. Water Environment \& Technology, Vol. 19, $\mathrm{n}^{\circ} 12$, DEC, 2007.

NOVAES, L.F. Estudo da influência da agitação e da estratégia de alimentação sobre o desempenho de um ASBR em escala piloto aplicado ao tratamento de esgoto sanitário. Tese de Doutorado apresentada na Escola de Engenharia de São Carlos, USP, São Carlos, 2008.

PARRY, D.L.; Fueling the flames. Water Environment \& Technology, Vol. 20, $n^{\circ}$ 9, SEPT, 2008.

PEÑA, M.R.; MARA, D.D.; AVELLA, G.P. Dispersion and treatment performance analysis of an UASB reactor under different hydraulic loading rates. Water Research, Volume 40, Issue 3, Feb. 2006.

POPPER, K. A lógica e a evolução da teória científica, palestra dada na Rádio da Alemanha do Norte a 7 de março de 1972. A vida é aprendizagem, Edições 70, Lisboa, 1999. 
